\title{
GÊNERO E MARXISMO: CONTRIBUIÇÕES PARA A HISTÓRIA DAS CIÊNCIAS
}

\author{
GÉNERO Y MARXISMO: CONTRIBUCIONES A LA HISTÓRIA DE LAS CIENCIAS
}

\section{GENDER AND MARXISM: CONTRIBUTIONS TO THE HISTORY OF SCIENCES}

DOI: http://dx.doi.org/10.9771/gmed.v12i1.38081

\author{
Carolina Queiroz Santana ${ }^{1}$ \\ Ingrid Silva de Andrade 2 \\ Victor Ferreira Dias Santos ${ }^{3}$
}

\begin{abstract}
Resumo: Neste ensaio teórico, questionamos: Qual a contribuição da teoria marxista e do feminismo marxista para a história das mulheres nas ciências? Para isso, revisamos os estudos de feminismo/marxismo e/ou gênero/marxismo, e propomos quatro teses para a história das mulheres nas ciências: 1. O Materialismo Histórico - Dialético refuta argumentos de superioridade masculina na ciência por mero essencialismo biológico; 2.A análise do feminismo marxista à categoria de gênero proporciona uma crítica a ciência pautada em determinações absolutas; 3 . O feminismo Marxista defende o espaço privado como esfera política; 4. A história social, sob um viés marxista, se configura como instrumento importante para a escrita de história das mulheres nas ciências.
\end{abstract}

Palavras-chave: Feminismo Marxista. História das Mulheres nas Ciências. Gênero e Ciência

Resumen: En este ensayo teórico, preguntas: ¿Cuál es la contribución de la teoría marxista y el feminismo marxista a la historia de la mujer en la ciencia? Con este fin, revise los estudios de feminismo / marxismo y / o género / marxismo, y proponga cuatro tesis para una historia de las mujeres en las ciencias: 1. La historia del materialismo - La dialéctica refuta los argumentos de superioridad masculina en la ciencia por su humanismo esencial; 2 . El análisis del feminismo marxista en la categoría de género proporciona una crítica de la ciencia basada en determinaciones absolutas; 3 . El feminismo marxista defiende el espacio privado como esfera política; 4. La historia social, bajo un marxista, es una herramienta importante para escribir la historia de la mujer en la ciencia.

Palabras clave: feminismo marxista. Historia de la mujer en la ciencia. Género y ciencia.

Abstract: In this theoretical essay, questions: What is the contribution of Marxist theory and Marxist feminism to the history of women in science? To this end, review the studies of feminism / Marxism and / or gender / Marxism, and propose four theses for a history of women in science: 1 . The History of Materialism - Dialectic refutes the arguments of male superiority in science for its essential humanism; 2. The analysis of Marxist feminism in the category of gender provides a critique of science based on absolute determinations; 3. Marxist feminism defends the private space as a political sphere; 4. Social history, under a Marxist, is an important tool for writing the history of women in science.

Keywords: Marxist feminism. History of Women in Science. Gender and Science.

\section{Introdução}

Os estudos de gênero têm crescido nas últimas décadas, desde percepções que o defende como um paradigma científico até que o consideram como uma categoria imprescindível para a análise histórica. $\mathrm{Na}$ história das ciências essa categoria ainda tem se mostrado um pouco tímida, apesar disso, algumas pesquisadoras entusiastas da área, como Margaret Rossiter e Evelyn Fox Keller, vêm se debruçando sobre tal discussão. Mas qual seria o real significado de "gênero"? Como esta categoria pode ser usada para entender e superar a opressão às mulheres? 
Inúmeras teóricas feministas buscaram respostas, especialmente nas últimas décadas do século XX. Dentre elas, as feministas marxistas, que defendem a necessidade de se pensar gênero atrelado à outras categorias e sob a lógica da reprodução do capital. Aos escritos de Marx e Engels, bastante tímidos em representar a situação da mulher na atual forma de sociabilidade, estas acadêmicas teceram críticas, bem como se apropriaram de categorias básicas do materialismo histórico-dialético, para mostrar que a opressão contra a mulher é um problema intrinsecamente ligado a estrutura do capitalismo. Em meio a debates que desacreditam da capacidade do marxismo em pensar a problemática de gênero, demonstraram que apesar de suas limitações, o método, presente nessa teoria, apresenta elementos importantes para discutir o lugar que a mulher ocupa na sociedade.

Às críticas a uma historiografia de base marxista não se encerram aos aspectos de gênero, mas se estendem às abordagens da história da ciência como um todo. Partindo de analises restritivas, a história marxista foi duramente acusada como economicista, de modo que não daria conta de analisar as diversas particularidades e singularidades como a ciência e o gênero. Apesar disso, foi principalmente sob uma história das ciências de viés marxista, que questões externalista da própria ciência começaram a ser levantadas, superando a querela entre história externalista e internalista das ciências (GAVROGLU, 2007; YOUNG, 1996; COLTURATO; MASSI,2019). Colturato e Massi (2019, p.176), apontam também para as especificidades do método marxista na história que possibilita "a identificação da unidade de análise e sua relação com o singular e com o universal para constituir as mediações particulares do fenômeno histórico, obtendo assim a síntese dos fenômenos históricos".

Mediante tais indícios, surge o questionamento que norteia essa pesquisa teórica: Qual a contribuição da teoria marxista e do feminismo marxista para a história das mulheres nas ciências? Percebemos que, algumas pesquisas tanto do materialismo histórico-dialético quanto das formulações das próprias feministas marxistas podem vir a contribuir com a presença de mais mulheres nas ciências, bem como um maior aprofundamento da área de gênero e ciência. Desse modo, apresentamos o debate a partir de quatro teses que trazem luz às nossas indagações. Antes disso, apresentamos alguns elementos que dizem respeito a relação entre marxismo e feminismo e aos estudos de gênero.

\section{Emancipação das mulheres e a teoria marxista}

Para entendermos a relação entre gênero e capitalismo, é importante saber, brevemente, como esse modo de produção funciona e no que se baseia. Capitalismo é, segundo a perspectiva marxista, um sistema econômico baseado no acúmulo de capital através da exploração dos trabalhadores/as, onde o explorador vai ter o excesso, a mais valia. Visa lucro e acumulação de riqueza e baseia-se na propriedade privada dos meios de produção. De acordo com Karl Marx a produção do capital “[...]não é apenas produção de mercadoria, é essencialmente produção de mais-valia. $\mathrm{O}$ trabalhador produz não para si, mas para o capital. Não basta, portanto, que produza em geral. Ele tem de produzir mais-valia. Apenas é produtivo o trabalhador que produz mais-valia para o capitalista ou serve à autovalorização do capital (Marx, 1984, p. 105-106). 
Na perspectiva de Marx, o que caracteriza o sistema capitalista é a transformação em capital de todos os meios de produção e a transformação de potenciais produtores diretos em mão de obra assalariada. No materialismo histórico-dialético, a humanidade é concebida a partir da relação dialética entre biológico e social, mediada pelo trabalho. Segundo Galvão, Lavoura e Martins (2019, p.47) essa atividade mediadora é compreendida:

[...] essencialmente social, pois produzimos e consumimos o seu resultado coletivamente, como gênero humano. Assim, mesmo em situações que aparentemente se trata de uma atividade individual, ela é sempre coletiva. Conforme Netto e Braz (2007), o trabalho nunca foi e nunca será uma atividade isolada, deslocada do conjunto da sociedade. Sua realização pressupõe não a existência de um sujeito isolado, que empreende o trabalho de maneira individualizada, mas sim um sujeito que se insere em determinado conjunto de relações sociais de produção que já não obedece a puros determinismos biológicos, orgânicos e naturais. Dessa maneira, a realização do trabalho, dada a sua especificidade, exige um tipo peculiar de vinculação entre os indivíduos, demarcando seu caráter coletivo, designando-o como atividade social.

Destarte, essa é a categoria fundante que nos diferencia dos outros seres vivos, e por isso tem importância central na compreensão da mulher enquanto ser social e a superação de concepções naturais que a colocam como inferior na sociedade. Desse modo, a mulher não pode ser considerada apenas um organismo determinado sexualmente, porque a consciência que a mulher adquire sobre ser mulher é um fato histórico e coletivo que reflete a forma que a sociedade é estruturada, e não apenas uma questão sexual (BEAVOUIR, 1970).

É a partir do entendimento do modo de produção capitalista que Safiotti explica que a inserção da mulher na sociedade capitalista ocorreu em condições contraditórias. As mulheres possuem duas desvantagens: a marginalização no sistema de produção e a subvalorização das capacidades femininas. $\mathrm{O}$ sexo acaba tendo uma única determinação e sendo algo positivo para o sistema capitalista (GONÇALVES 2011). Apesar dessa contradição, o capitalismo abriu as "portas do emprego" para as mulheres. Referimonos a emprego, pois, as mulheres sempre trabalharam, no sentido ontológico da formação do ser social, mesmo que em funções diferentes das desempenhadas pelos homens (SAFIOTTI, 2000).

Mas aqui, destacamos que a princípio existia uma divisão do trabalho, sem desigualdade. Os homens caçavam e as mulheres cuidavam do lar. Quando o homem precisava de um trabalho mais intensivo, acabava recorrendo a outros homens, o que foi uma das determinações para surgimento da propriedade privada. O homem se torna proprietário desses outros homens e também da mulher, o que é visto como a "grande derrota do sexo feminino". A mulher se torna confinada no trabalho doméstico e o direito à propriedade é transmitido de pai para filho. Daí surge a família patriarcal, que é baseada na propriedade privada. A igualdade entre os sexos só poderia retornar, de forma aparente, quando a mulher pudesse participar da atividade pública, o que -supostamente - aconteceria no capitalismo. (BEAVOUIR, 1970).

Apesar da crença de que o capitalismo proporcionaria a emancipação das mulheres, devido sua inserção no mercado de trabalho, na prática se percebe o contrário. As características de gênero acabam hierarquizando os membros a partir de uma escala de valores, agindo de acordo com a necessidade do sistema produtivo. Marx lamenta pelas péssimas condições de trabalho da mulher, porém, sua preocupação 
é apenas com a educação dos filhos. Ele considerava prejudicial a destruição da família, antes que surgisse uma nova forma de estrutura-la (GONÇALVES, 2011).

Marx e Engels não conseguiram solucionar o problema da mulher uma vez que não deram atenção às atividades exercidas pelas mulheres em casa. Além da marginalização feminina do trabalho no sistema produtivo capitalista, a mulher se encontra nessa estrutura familiar na qual exerce atividade doméstica e de cuidado com os filhos. Apesar disso, Gonçalves (2011) concorda com Marx quando este afirma que o problema da mulher não é isolado, e sim, decorrente do sistema de produção que se sustenta a partir da opressão do homem pelo próprio homem, além da alienação ${ }^{4}$ proveniente do sistema.

Para Marx e Engels, a mulher escrava apenas pode se libertar a partir de um processo geral de humanização de toda a sociedade. Isso implica o fim da família da forma que é estruturada. Apesar de considerar que a ascensão do capitalismo promoveria um novo tipo de familia, graças a permissão da mulher trabalhar fora, se percebe que a mulher continua "presa" ao lar. É inocente considerar que a liberdade econômica da mulher fosse suficiente para acabar com as opressões de gênero. No capitalismo, a exploração da força de trabalho continua a ser diferenciada de acordo com o sexo. A inferiorização das mulheres não surgiu no capitalismo, porém, este se aproveita da grande quantidade de mulheres ao intensificar a disputa e gerar ainda mais desigualdade entre os gêneros. Sendo assim, o desenvolvimento do capitalismo não significa um avanço nas condições sociais das mulheres. O capitalismo até pode permitir mudanças, mas não necessariamente uma transformação radical dessa desigualdade historicamente constituída. As condições de gênero acabam sendo uma desvantagem no processo de competição e um mecanismo para a preservação da estrutura de classes (GONÇALVES, 2011).

De acordo com Marx e Engels, dentro da própria estrutura da sociedade existe uma divisão natural do trabalho, entre homens e mulheres. Segundo Moraes (2000), no Manifesto Comunista, os autores continuam a afirmar a questão da opressão à mulher na família. Para os autores do comunismo, acabar com a família da atual forma que é estruturada seria uma das metas de um sistema comunista, assim a emancipação da mulher estaria estreitamente ligada a ascensão do comunismo e a derrota do capitalismo.

\section{Gênero como categoria analítica}

Dentro da lógica feminista a categoria "Gênero" foi ganhando espaço ao longo do tempo como um instrumento promissor. As feministas marxistas também se debruçaram sobre essa categoria, utilizandoa sempre que possível. Apesar disso, críticas foram tecidas por estas autoras a tal categoria, diante da sua ampla utilização baseada em princípios pós-estruturalistas que negam a materialidade e apresentam gênero como uma unidade totalizadora.

A transição dos "estudos sobre as mulheres" para os "estudos de gênero" marca a migração da problemática feminina dos espaços de debates da militância feminista nas ruas para o espaço da academia (MORAES, 2000). Fruto de um projeto liberal, que atrelava a emancipação feminina ao próprio sistema capitalista, "a institucionalização, a onguização e a burocratização do movimento feminista tomou tal amplitude que assistimos a sua própria despolitização" (GONÇALVES, 2009, p. 106). A preocupação se 
desloca da luta pela superação de situação de opressão para o entendimento científico das bases dessa opressão (GONÇALVES, 2011).

A inquietação feminista acadêmica se concentrava na busca por um conceito que possibilitasse estudar as causas da opressão feminina de forma mais ampla que o viés economicista apontado pela análise de classes sociais. Assim, gênero, supostamente seria a palavra mais adequada nesse embate. "Apesar de importantes diferenças, todos os significados modernos de gênero se enraízam na observação de Simone de Beauvoir de que "não se nasce mulher" e nas condições sociais do pós-guerra que possibilitaram a construção das mulheres como um coletivo histórico, sujeito-em-processo" (HARAWAY, 2004, p.211). Assim, gênero é um conceito desenvolvido para contestar a naturalização da diferença sexual. Nesse sentido, apesar desse conceito não se encontrar nos escritos de Engels e Marx, suas produções ofereceram instrumentos importantes para as teorizações sobre gênero (HARAWAY, 2004).

De acordo com Araújo (2000, p.68), o conceito de gênero surge "da tentativa de compreender como a subordinação é reproduzida e a dominação masculina é sustentada em suas múltiplas manifestações", gênero possibilitaria fugir do determinismo biológico ou da ótica puramente economicista e ainda agregar a dimensão simbólica às práticas materiais. Assim, poderia ser encarado como um importante recurso analítico, inclusive por feministas marxistas, para "a construção/desconstrução das identidades de gênero, isto é, os caminhos através dos quais os atributos e lugares do feminino e do masculino são social e culturalmente construídos, muito mais como significados que como essência” (ARAÚJO, 2000, p.69).

Apesar de promissora, tal categoria guardava problemáticas quando geridas por bases pósestruturalistas. A primeira seria a ênfase na dimensão simbólica deslocada de bases materiais, "Gênero deixa de ser um conceito meio, isto é, uma forma de ampliar o olhar e entender a trajetória em torno da qual a dominação foi se estruturando nas práticas materiais e na subjetividade humana, para se tornar um conceito totalizador" (ARAÚJO, 2000, p. 69). A tendência em tornar gênero uma "entidade global e totalizante" negligenciando outros marcadores sociais, teve sua limitação exatamente no distanciamento, entre a discussão teórica e o movimento popular das mulheres, ou seja, “'teorias’ são vazias de sentido ao limitarse em um 'academicismo"' (CISNE, 2005, p.1).

Castro (2000), afirma que de forma irônica, gênero é, hoje, um conceito congelado que se reduz a um termo de posição. Nesse mesmo sentido, Araújo (2000, p.69), alerta que "gênero passou a descrever muito e explicar muito pouco, pois como conceito, tendeu a ser auto-referido", de modo que tudo se torna relativo. A esse caminho percorrido pelos estudos de gênero pouco se cabe para o feminismo marxista, não perdendo de vista que, as formas de opressão relacionadas à gênero “[...] são uma realidade objetiva que atinge um contingente expressivo de mulheres e, neste sentido, só pode ser entendida no contexto sóciohistórico-cultural, num movimento complexo e contraditório entre sociabilidade e individualidade e entre as relações de gênero e a totalidade da vida social (SANTOS; OLIVEIRA, 2010, p. 12).

Ou seja, não faz sentido pensar em gênero desvinculado do combate à ordem econômica sob a qual se assenta a sociedade. E mesmo que a superação da atual forma de sociabilidade não garanta o fim das desigualdades entre homens e mulheres, o caminho para tal não pode ser atrelado a um conceito único e totalizador seja ele "classe social" ou "gênero". Saffioti, já na década de 90, alertava para a necessidade de 
se pensar a complexidade da opressão feminina e até mesmo a opressão da classe proletária como um nó de três contradições sociais básicas: gênero, raça/etnia e classe social. Nossa sociedade se divide em classes sociais, mas também é atravessada por outras contradições. "Não se trata, contudo, de conceber três diferentes ordenamentos das relações sociais correndo paralelamente. Ao contrário, estas três contradições entrelaçadas pelo nó sustentam a manutenção do sistema capitalista" (GONÇALVES, 2011, p. 120).

Este pode ser apontado como o principal desafio do marxismo, ou seja, agregar "a complexidade e as dimensões de conflitos que foram surgindo com a modernidade, gerando diversidade de sujeitos políticos e conformando manifestações variadas de subjetividade e interesses, com dimensões políticas específicas" (ARAÚJO, 2000, p.70). Além disso, re-entrelaçar o projeto acadêmico feminista ao movimento e à reivindicação das mulheres das camadas populares, inter-relacionando teoria e prática em uma perspectiva totalizadora que abarque os conceitos em sua perspectiva analítica e histórica e não apenas como um fim em si mesmo.

\section{Contribuições para a história das ciências}

As discussões que relacionam feminismo/marxismo e/ou gênero/marxismo são infinitas, se tornando um campo amplamente estudado e investigado. Apesar disso, tais discussões ainda são restritivas ao campo das ciências humanas e sociais, demarcando a necessidade de refletir esses aspectos nas ciências exatas da natureza. Pesquisadoras/es desta última tem demonstrado um crescente interesse pelas questões de gênero principalmente ao refletir o viés de neutralidade atribuído a ciência. Os estudos que agregam gênero e ciências, buscavam em sua base, duas premissas comuns: primeiro questionar a própria ciência concebida historicamente sob uma ótica machista e misógina; segundo, questionar que lugar ocupava as mulheres na ciência e garantir mais espaço para elas.

Acadêmicas feministas, como, Evelyn Fox Keller, Londa Schiebinger e Donna Haraway, argumentam que muito na ciência já foi mudado desde que suas bases passaram a ser questionadas pelo movimento feminista. O movimento feminista nunca se constituiu como único e fluido, sendo impossível pensar-se em uma única "teoria feminista" é nesse sentido que nos debruçamos sobre nosso problema de pesquisa: Qual a contribuição da teoria marxista e do feminismo marxista para a história das mulheres nas ciências? Adotamos para isso quatro teses, que são formuladas a partir de princípios do próprio materialismo histórico-dialético e de questões postas por feministas marxistas que agregaram aos estudos primordiais do marxismo as problemáticas das mulheres.

\section{O Materialismo Histórico - Dialético refuta argumentos de superioridade masculina na ciência por mero essencialismo biológico}

Podemos dizer que para o Materialismo Histórico-Dialético a humanidade se constitui de sujeitos históricos, moldados pelo real através da modificação da natureza. Lessa e Tonet (2011) afirmam que, essa relação dialética entre humanidade e natureza tem seu fundamento no trabalho. Desse modo "por meio do trabalho, os homens [a humanidade] não apenas constroem materialmente a sociedade, mas também lançam 
as bases para que se construam como indivíduos" (LESSA; TONET, 2011, p.17, grifos nossos). O ser humano, é um ser social, assim distingue-se dos outros animais, possuindo "leis de desenvolvimento histórico completamente distintas das leis que regem os processos naturais" (LESSA; TONET, 2011, p.18).

Nesse sentido, Simone de Beauvoir, já em seu livro "O segundo sexo" ao se referir ao materialismo histórico, argumentava:

A humanidade não é uma espécie animal: é uma realidade histórica. A sociedade humana é uma anti-phisis: ela não sofre passivamente a presença da natureza, ela a retoma em mãos. Essa retomada de posse não é uma operação interior e subjetiva; efetua-se objetivamente na praxis. Assim, a mulher não poderia ser considerada apenas um organismo sexuado: entre os dados biológicos só têm importância os que assumem, na ação, um valor concreto; a consciência que a mulher adquire de si mesma não é definida unicamente pela sexualidade. Ela reflete uma situação que depende da estrutura econômica da sociedade, estrutura que traduz o grau de evolução técnica a que chegou a humanidade. Viu-se que, biologicamente, os dois traços que caracterizam a mulher são os seguintes: seu domínio sobre o mundo é menos extenso que o do homem; ela é mais estreitamente submetida à espécie. Mas esses fatos assumem uma valor inteiramente diferente segundo o seu contexto econômico e social. Na história humana, o domínio do mundo não se define nunca pelo corpo nu: a mão com seu polegar preensivo já se supera em direção ao instrumento que lhe multiplica o poder; desde os mais antigos documentos de pré-história o homem surge sempre armado. (BEAUVOIR, 2019, p.83)

Apesar das limitações da abordagem de Engels em "A origem da família" que deixa de lado fatores relevantes no que cerne a sexualidade, muitos pontos desse texto são interessantes para sustentar nossa tese,

É de acordo com essa perspectiva que Engels retraça a história da mulher em A Origem da Família. Essa história dependeria essencialmente da história das técnicas. Na Idade da Pedra, quando a terra era comum a todos os membros do clã, o caráter rudimentar da pá, da enxada primitiva, limitava as possibilidades agrícolas: as forças femininas estavam na medida do trabalho exigido pelo cultivo dos jardins. Nessa divisão primitiva do trabalho, os dois sexos já constituem, até certo ponto, duas classes; entre elas há igualdade. Enquanto o homem caça e pesca, a mulher permanece no lar. Mas as tarefas domésticas comportam um trabalho produtivo: fabricação dos vasilhames, tecelagem, jardinagem, e com isso ela desempenha um papel importante na vida econômica. Com a descoberta do cobre, do estanho, do bronze, do ferro, com o aparecimento da charrua, a agricultura estende seus domínios. Um trabalho intensivo é exigido para desbravar florestas, tornar os campos produtivos. O homem recorre, então, ao serviço de outros homens que reduz à escravidão. A propriedade privada aparece: senhor dos escravos e da terra, o homem torna-se também proprietário da mulher. Nisso consiste "a grande derrota histórica do sexo feminino". Ela se explica pelo transtorno ocorrido na divisão do trabalho em conseqüência da invenção de novos instrumentos. (BEAUVOIR, 2019, p. 84)

O fator central da suposta "inferiorização" e "subordinação" da mulher, se concentra em uma questão que não é natural, mas sim, de caráter histórico. As condições biológicas, como, a maternidade, trazem seu peso nesse processo de “derrota histórica”, mas não há nenhum argumento que possa sustentar a ideia de que há atividades endereçadas a homens e mulheres pautadas em um essencialismo biológico. Pelo contrário, é a lógica da hierarquização do homem sobre a mulher, que determina tais papéis. E nesse sentido, lugares que garantem status de poder poucas vezes são atribuídos às mulheres, e aí se encontra a nossa ciência. Os argumentos ao longo da história foram os mais variados, desde a incapacidade de racionalizar sobre questões lógicas até a pouca probabilidade de desenvolver abstrações matemáticas. A análise materialista histórico-dialética permite situar a mulher em um outro espectro, de modo que é preciso, ao historicizar a ciência, levar em conta que ela nos foi tirada por mero capricho de dominação e de poder. 
Percebemos que ao enfatizar o real, com base no movimento histórico, o materialismo históricodialético permite "desnaturalizar" a mulher. A cultura é entendida como superior a natureza assim a ela ligase a figura masculina, já a mulher entendida como natureza, condutora do processo de reprodução. A superação desse paradigma, permitiu se pensar a história das ciências em algumas escalas, especialmente no que diz respeito aos aspectos da reprodução humana (HARAWAY, 2004).

A manutenção e o cuidado com essa reprodução é direcionada a mulher, pois isto lhes é natural. Ao considerar assim, a maternidade passa a ser a principal ocupação da mulher, sendo que esta nem mesmo é reconhecida como "tipo de trabalho", extingue-se assim as chances da mulher em acender em outras carreiras, já que está responsabilidade não é compartilhada com o homem na divisão sexual do trabalho. $\mathrm{Na}$ paternidade o homem é livre, na maternidade a mulher é serva. Mesmo com reformulações, das relações de trabalho, as mulheres ainda vivenciam duplas jornadas, e são muitas vezes obrigadas a escolher entre a "servidão da maternidade" e suas "carreiras científicas", quando tentam conciliar ambas as coisas, são inúmeras vezes acusadas de fracassar (HARAWAY, 2004).

\section{A análise do feminismo marxista à categoria de gênero proporciona uma crítica a ciência pautada em determinações absolutas}

Dentro da história das ciências gênero foi adotado, como um instrumento de diferenciação do sexo biológico (KELLER, 1995). A categoria de gênero é um elemento importante para essa desnaturalização da diferença sexual. Apesar disso, não pode se encerrar em si própria, sendo necessário a análise de múltiplas determinações para compreender como as situações de opressão se acentuam na sociedade capitalista. Na história das mulheres das ciências, percebemos, que a situações de negligências não se encerram na questão de gênero ou classe, mas são perpassadas por múltiplas determinações que compõem o jogo de interesses da sociedade capitalista, distintos diante das particularidade de cada ser social.

Mediante as discussões sobre gênero apresentadas nesse texto, acreditamos que gênero pode sim ser visto com um conceito importante para a inserção das mulheres na história, mas deve ser feito de forma relacional e dialética com outras determinações presentes na realidade. Não basta colocá-lo como um conceito imperial, se faz necessário pensar em todas as dimensões complexas que constituem a nossa base sócio econômica concreta. Não podemos permitir que gênero se torne mais uma categoria angariada por um projeto liberal para a reprodução constante do modelo capitalista e patriarcal (ARAÚJO, 2000).

\section{O feminismo Marxista defende o espaço privado como esfera política}

Dentre os argumentos para a exclusão das mulheres na história das ciências, encontra-se que as mulheres não são inscritas na história pois não estavam no palco central onde esta acontecia. Remetendo assim, ao debate entre a esfera pública e a esfera privada. A historiografia, concentrou seus estudos na esfera pública utilizando a teoria desta ser mais política. $\mathrm{O}$ argumento defendido pelo feminismo marxista é que esse espaço privado direcionado às mulheres é tão político quanto o espaço público considerado centro da história. Foi no espaço privado, principalmente, que muitas mulheres fizeram história, que foram roubadas 
intelectualmente por seus maridos, filhos e pais, e além de tudo foi na esfera privada que as mulheres começaram a se organizar enquanto movimento político.

Em uma análise da teoria política Okin (2008), se propõem a questionar as dicotomias entre o público e o privado. Para isso ela ressalta que a ideia da diferenciação entre público e privado, como sendo duas esferas completamente opostas surge de um ideário liberal. Remetendo a história do feminismo, Okin, relata que foi com a ascensão da esquerda no poder, a ascensão de uma história com viés marxista, que a esfera privada começou a ser vista como indissociável da esfera pública, mesmo que estes não se concentrassem nas relações de gênero embutidas nessas esferas. Paralelamente, o movimento feminista começou a argumentar sobre o poder e as práticas políticas da esfera privada, destacando-se o bordão "o pessoal é político".

\section{A história social, sob um viés marxista, se configura como instrumento importante para a escrita de história das mulheres nas ciências}

A Escola dos Annales instaurou uma ruptura na historiografia, iniciada na França a partir dos anos de 1930. Esses escritores se baseavam em três ideias centrais: "a substituição da tradicional narrativa de acontecimentos por uma história-problema. [...] a história de todas as atividades humanas e não apenas a história política. [...] a complementação com outras disciplinas” (BURKE, 2013, p.15). A partir dos anos 1970 com a terceira geração da escola, conhecida como Nowvelle Historie, ocorreu maior receptividade a dimensão sexuada no interior da evolução histórica, nesse quadro, temas, como bruxaria, prostituição, loucura, aborto, parto, maternidade, entre outros, começaram a ter destaque inicialmente a partir de um padrão masculino da história social (RAGO, 1998).

A partir dos 1980, a história social recebe duras críticas quanto a sua utilização diante da categoria de gênero, principalmente por parte de Joan Scott (1986), que argumentava a necessidade de pensar as relações gênero sob uma lógica pós-estruturalista. Carla Pinsky (2009), se propõe a analisar as considerações de Scott, e traçar argumentos justificando a adequação da história social nos estudos sobre gênero e história das mulheres. Busca apresentar elementos que mostram como o pós-estruturalismo proposto por Scott, que se concentra nos aspectos da linguagem e do discurso, e não na materialidade real, não é suficiente para resolver a emergência histórica das mulheres.

Em geral, os críticos valorizam o trabalho de Scott e comungam de suas preocupações políticas. [...] mas grande parte não se convence dos argumentos em favor do pósestruturalismo. Para eles, o problema principal não está nas questões que Scott apresenta, mas na abordagem que propõe para resolvê-las. Consideram que ela foi "injusta" ao depor a História Social e insistem nas possibilidades positivas dessa linha de pesquisa. Uma das críticas mais recorrentes e interessantes diz respeito à deficiência das ferramentas teóricas pós-estruturalistas diante da questão da ação humana. Tal deficiência acentua-se quando se tenta casar essa abordagem com um projeto político como o explicitado por Scott, qual seja, romper com os determinismos, fazer das mulheres sujeitos históricos e fornecer elementos para se questionarem as desigualdades de gênero. Caracteriza-se aí uma contradição. [...] Como pode haver ação se há somente sujeitos/objetos produzidos discursivamente? Como estudar rupturas e resistências se a ação humana parece dissolver-se diante dos onipresentes "sistemas discursivos"? Ao pressupor que a ação ocorre dentro de uma linguagem conceitual que estabelece por si 
limites e contém, ela própria, possibilidades de negação, resistência e interpretação, como reconhecê-los? (PINSKY, 2009, p.175)

Nesse sentido, segundo Tilly (1994) "para alcançar seus objetivos tanto no domínio do conhecimento quanto no do político, a história das mulheres tem a necessidade de empregar os métodos de análise da história social, além de usar a descrição e o conceito de gênero” (p.51). A história social defendida por Tilly seria "uma história que coloque problemas, descreva e analise os dados disponíveis, e explique. Uma história que trate das grandes questões históricas e contribua para resolver problemas já inseridos na agenda da história." (p. 52). Essa autora destaca que a utilização do conceito de gênero chamou atenção para as relações de poder existente, e a história social analítica, voltada para a resolução de problemas, atribui dois outros aspectos importantes da história das mulheres: completar a descrição e a interpretação com a explicação; vincular seus resultados aos problemas atuais mais gerais.

\section{Considerações finais}

O materialismo histórico-dialético, especialmente sob uso das feministas marxistas permitiu alguns avanços para se pensar a situação da opressão da mulher na sociedade capitalista. Ao colocar em foco a Histórica Ciência, percebemos que a teoria marxista torna-se um instrumento poderoso para contestar argumentos que reduzem a mulher ao sexo e a determinações biológicas.

Defendemos nesse trabalho três hipóteses que mostram as contribuições a teoria marxista e das feministas marxistas para a história das mulheres nas ciências, sendo elas: 1. O Materialismo Histórico Dialético refuta argumentos de superioridade masculina na ciência por mero essencialismo biológico; 2.A análise do feminismo marxista à categoria de gênero proporciona uma crítica a ciência pautada em determinações absolutas; 3. O feminismo Marxista defende o espaço privado como esfera política; 4. A história social, sob um viés marxista, se configura como instrumento importante para a escrita de história das mulheres nas ciências.

\section{Referências}

ARAÚJO, Clara. Marxismo, feminismo e o enfoque de gênero. Crítica Marxista, v. 11, 2000.

BEAUVOIR, Simone. O segundo sexo. v.1. Nova Fronteira, 2019.

BENOIT, Lelita Oliveira. Feminismo, gênero e revolução. Crítica Marxista, v. 11, 2000.

CISNE, Mirla. Marxismo: uma teoria indispensável à luta feminista. In: $4^{\circ}$ Colóquio Marx e Engels, 2005.

COLTURATO, Andriel Rodrigo; MASSI, Luciana. Aportes teóricos e metodológicos para a história da ciência com base no materialismo histórico-dialético. Germinal: Marxismo e Educação em Debate, v. 11, n. 3, p. 170-180, 2019.

GAVROGLU, Kostas. O passado das ciências como história. Tradução de Custódio Magueijo. Porto: Porto Editora, Coleção História e Filosofia da Ciência, 2007.

GONÇALVES, Renata. Sem pão e sem rosas: do feminismo marxista impulsionado pelo Maio de 1968 ao academicismo de gênero. Lutas Sociais, n. 21/22, p. 98-110, 2009. 
GONÇALVES, Renata. O feminismo marxista de Heleieth Saffioti. Lutas Sociais, n. 27, p. 119-131, 2011.

HARAWAY, Donna. "Gênero" para um dicionário marxista: a política sexual de uma palavra. Cadernos pagu, n. 22, p. 201-246, 2004.

MARX, Karl. O capital. v. I, tomo 2. São Paulo: Abril Cultural, 1984.

MORAES, Maria Lygia Quartim. Marxismo e feminismo no Brasil. Campinas: Unicamp, collection Primeira Versão, 1996.

MORAES, Maria Lygia Quartim. Marxismo e feminismo: afinidades e diferenças. Crítica Marxista, v. 1, n. 11, p. 89-97, 2000.

SANTOS, Silvana Mara de Morais dos; OLIVEIRA, Leidiane. Igualdade nas relações de gênero na sociedade do capital: limites, contradições e avanços. Revista Katálysis, Florianópolis, v. 13, n. 1, p. 11 $19,2010$.

TONET, Ivo; LESSA, Sérgio. Introdução à filosofia de Marx. São Paulo, 2008.

YOUNG, Robert Maxwell. Marxism and history of science. In: OLBY, R.C. et al. (eds.) Companion to the history of modern science. London: Routledge, 1996. p. 77-86.

\section{Notas}

1 Professora (Substituta) no curso de Licenciatura em Química na Universidade Federal do Recôncavo da Bahia - Centro de Formação de Professores. Graduada em Licenciatura em Química na Universidade Federal do Recôncavo da Bahia - Centro de Formação de Professores. Mestranda no Programa de Pós-Graduação em Ensino História e Filosofia da Ciência na Universidade Federal da Bahia. Plataforma Lattes: CV: http://lattes.cnpq.br/8055657565670702 Orcid: https://orcid.org/0000-0003-14640490 Email: carolinaufrb@gmail.com

2 Possui graduação em Licenciatura em Química, pela Universidade Federal da Bahia. Mestranda no Programa de Pós-Graduação em Ensino História e Filosofia da Ciência na Universidade Federal da Bahia. CV: http://lattes.cnpq.br/7845350589665775 Orcid: http://orcid.org/0000-0002-5255-326X E-mail: dindis2@hotmail.com

${ }^{3}$ Graduado em Licenciatura em Química no Instituto de Química da Unesp Araraquara. Participou do programa de iniciação a docência, PIBID, como bolsista, atuando em escolas publicas de Araraquara. Foi bolsista CNPq no projeto que teve como objetivo investigar as contribuições do mestrado profissional no ensino de ciências para o desenvolvimento profissional docente. Além disso também atuou como bolsista em projeto de extensão sobre a produção de sabão com alunos do assentamento Monte Alegre localizado em Araraquara. Atualmente está cursando o Mestrado no Programa de Pós-Graduação em Ensino História e Filosofia da Ciência na Universidade Federal da Bahia. CV: http://lattes.cnpq.br/6147913017115860 Orcid: https://orcid.org/0000-0001-8645-7420 Email: victor.f.dias@globomail.com

4 Para um maior aprofundamento nessa categoria essencial no pensamento marxista, ler: MARX, K.; ENGELS, F. A ideologia alemã: crítica da mais recente filosofia alemã em seus representantes Furbach, B. Bauer e Stirner, e do socialismo alemão em seus diferentes profetas (1845-1846). São Paulo: Boi Tempo, 2007. 616 p. Rubens Enderle, Nélio Schneider, Luciano Cavini Martorano. 